\title{
Time course of chord priming
}

\author{
HASAN GÜRKAN TEKMAN and JAMSHED J. BHARUCHA \\ Dartmouth College, Hanover, New Hampshire
}

\begin{abstract}
The time course of chord priming was explored in four experiments. In chord priming, a chord (a typical combination of simultaneously sounded tones) primes other chords that are musically related. In the present study, the prime duration and the stimulus onset asynchrony (SOA) between the prime chord and the chord to be judged were varied. Priming occurred at an SOA and prime duration as short as $50 \mathrm{msec}$, the shortest tested. When the prime duration was held constant at $50 \mathrm{msec}$, priming occurred at an SOA as long as $2,500 \mathrm{msec}$, the longest tested, and the magnitude of the priming effect did not diminish. To eliminate a possible role of sensory memory in maintaining the priming effect during the silence following the prime, a $250 \cdot \mathrm{msec}$ noise mask was presented immediately following the 50 -msec prime. The interpolated noise mask did not eliminate priming, thereby supporting the view that chord priming is the consequence of associative activation.
\end{abstract}

A musical chord (a typical combination of simultaneously occurring tones) facilitates the processing of chords that typically follow and enhances their perceived consonance (Bharucha \& Stoeckig, 1986). How rapidly does a chord induce this priming effect, and how long after the offset of the prime does priming persist? In this paper, we report an initial exploration into the buildup and persistence of priming over time, thereby attempting to determine its temporal boundary conditions.

Priming underlies the implications and expectations generated by a musical context. The fulfillment and violation of implications and expectations are thought by many (e.g., Meyer, 1956) to be important components of the aesthetic appreciation of music in a familiar genre.

Priming cannot be explained solely by the acousticspectral similarity between chords that prime each other, because it persists when all known acoustical similarity is removed (Bharucha \& Stoeckig, 1987). It thus seems to be the consequence of associations-presumably learned-at a cognitive level. The magnitude of the priming effect increases systematically with the closeness of the musical relationship between the prime and the target (Bharucha, 1987b), mirroring data obtained from memory confusions and subjective judgments of relatedness (Bharucha \& Krumhansl, 1983; Krumhansl, Bharucha, \& Castellano, 1982).

A possible explanation for chord priming is that events in a musical context activate representational units. Activation spreads to units that represent events that typically occur in that context (Bharucha, 1987a, 1987b). Networks

\footnotetext{
This research was supported by Grant BNS-8910778 to the second author from the National Science Foundation. The authors thank Annie Takeuchi for helpful suggestions and Jennifer Huska for her help in testing subjects. Correspondence may be addressed to either author at Department of Psychology, Dartmouth College, Hanover, NH 03755 (e-mail: tekman@dartmouth.edu or bharucha@dartmouth.edu).
}

of associated units that exhibit this property can be acquired by mechanisms for passive perceptual learning driven by extended exposure to the highly patterned auditory environment (Bharucha, 1991). This view is supported by the observation that priming is not limited to subjects with formal musical training (Bharucha \& Stoeckig, 1986). Priming thus reflects a robust underlying system that can be acquired without formal instruction.

The priming paradigm employed in this study utilizes an intonation judgment as reported by Bharucha and Stoeckig (1986, Experiments 2 and 3). Subjects decided whether a chord was in tune (a target) or out of tune (a foil). Mistuning was achieved by slightly changing the pitch of one of the three components of the chord. The chord judged for its intonation was preceded by another chord, called the prime chord. The two chords were either related or unrelated. The root tones of the related chord pairs were separated by a musical interval of a perfect fifth (seven semitones or a frequency factor of $2^{7 / 12}$ ). The root tones of the unrelated chord pairs were separated by a musical interval of a tritone (six semitones or a frequency factor of $2 \%$ ). These pairs are defined as related or unrelated on the basis of their high or low transition probabilities in the most pervasive forms of Western music; their labels as related or unrelated are also corroborated by relatedness judgments given by subjects hearing pairs of chords in sequence (Bharucha \& Krumhansl, 1983; Krumhansl, Bharucha, \& Castellano, 1982).

The effect of the relatedness of the pair of chords on the intonation judgment was of primary interest. The intonation judgment was employed in order to make inferences about the role of relatedness in the processing of chord sequences. The fact that Bharucha and Stoeckig $(1986,1987)$ found effects of relatedness on intonation judgments testifies to the presence of a process that evaluates harmonic relationships in chord sequences. This process appears to be operating even when it is not relevant to the task at hand. Hence, this process seems to be a 
general feature of listening to music or music-like stimuli that does not need to be called up consciously.

The result that we have called a priming effect is faster reaction times and/or fewer errors in judging the intonation of a chord when it is preceded by a related rather than an unrelated prime chord or a greater tendency in this direction for targets than for foils. The responses for foils indicate the extent to which the priming effect reflects a bias to hear the chord as being in tune when related and as being out of tune when unrelated. Bharucha and Stoeckig (1986) found a main effect of relatedness, such that overall responses were faster and more accurate when the target was preceded by a related prime. They also found an interaction between relatedness and intonation, such that subjects were faster and more accurate in judging a target to be in tune when it was related than when it was unrelated, with the opposite tendency for foils. Both effects constitute evidence of a representation of chord relationships.

The aim of the following experiments was to trace the time course of the buildup of priming by varying the prime duration and the stimulus onset asynchrony (SOA) between the two chords.

\section{EXPERIMENT 1}

In Experiment 1, the relationship between the duration of the prime and the magnitude of the priming effect was explored. Prime chords of different durations preceded the chord to be judged with no interstimulus interval (ISI). The duration of the prime was thus equal to the SOA between the two chords.

\section{Method}

Subjects. The subjects were 18 undergraduates at Dartmouth College who participated in the experiment for extra credit in an introductory psychology course. They had an average of 3.61 years of experience with a musical instrument or voice, with a range from 0 to 9 years. All subjects reported having normal hearing, and none reported having absolute pitch.

Apparatus. Stimuli were created by an Apple Macintosh II computer. A Sansui A-707 amplifier and Sennheiser HD-410 headphones were used for stimulus presentation.

Stimuli. Stimuli were major chords synthesized according to equal tempered tuning (in which one semitone corresponded to a frequency factor of $2^{1 / 12}$ ). A major chord consists of three component chromas: the root, the third (root $\times 2^{4 / 12}$ ), and the fifth (root $\times 2^{7 / 12}$ ). Each of the three chromas was represented by a tone in each octave of a five-octave range. Loudness of the tones tapered off to the hearing threshold in the outer octaves (after Krumhansl, Bharucha, \& Kessler, 1982; Shepard, 1964), factoring in the relationship between pitch, amplitude, and perceived loudness (Fletcher \& Munson, 1933). This method maximizes the sense of chroma and minimizes the effect of pitch height. Each component tone was a complex tone that included the first four harmonics at equal amplitudes.

The out-of-tune chords were created by reducing the frequency of the fifth in a major chord by an amount corresponding to $3 / 8$ of a semitone (i.e., a frequency factor of $2 \frac{3 / 96}{\text { ). }}$.

Procedure. The subjects were given a training session to ensure that they could discriminate in-tune and out-of-tune chords at a cri- terion level of accuracy. In each training trial, a chord was played for $2 \mathrm{sec}$, and the subjects were required to press one of two keys on the computer keyboard, signifying either "in tune" or "out of tune." The training session consisted of 48 trials, and the criterion number of correct responses was 43 (approximately $90 \%$ of the trials.) The subjects who performed below the criterion level were given a choice of repeating the training or withdrawing from the experiment. Only the subjects who performed at or above the criterion level participated in the actual experiment. Feedback about the accuracy of responses was presented after every trial in the training session and in the main experiment.

In the main experiment, each trial began with a sequence of 16 tones whose pitches were chosen at random. All tones were of equal duration, and the whole sequence lasted 2 sec. This was intended to erase possible effects of memory for the chords from the preceding trial. After a short silence of variable duration, two chords were played without any break in between. The subjects were instructed to decide whether the second chord was in tune or out of tune and to respond with a keypress as in the training. The three different durations of the prime chord were 111,333 , and $1,000 \mathrm{msec}$. The time from the onset of the random sequence to the onset of the chord to be judged was held constant at $5 \mathrm{sec}$. The chord to be judged was always played for $2 \mathrm{sec}$. The subjects were instructed to respond during the $2 \mathrm{sec}$ that the chord was played.

There were two types of pairs of chords. In the related trials, the root tones of the two chords were separated by 7 semitones (an interval of a perfect fifth, or a frequency factor of $2 \%$ ); in the unrelated trials, the roots of the two chords were separated by 6 semitones (an interval of a tritone, or a frequency factor of $2 \% 12$ ).

The design was completely crossed, with two levels of relatedness (related vs. unrelated), two levels of intonation (in tune vs. out of tune), and three prime durations. There were 18 replications of each of the 12 conditions, yielding 216 trials. The root tone of the prime chord, and, hence, the target chord, was chosen randomly from the 12 chromatic tones for each trial. The order of the 216 trials was chosen randomly for each subject.

To familiarize the subjects with the task, a sequence of 12 practice trials preceded the experiment. The practice trials consisted of one example of each condition, presented in random order.

\section{Results}

For each subject, the mean of the reaction times and the percentage of errors in each condition was calculated. Reaction times (RTs) for incorrect responses were not included in these averages. The responses that were made after the offset of the chord were also excluded.

Average reaction times and percentages of correct responses for Experiment 1 can be found in Figure 1. Reaction times and error percentages were analyzed in two separate repeated measures analyses of variance (ANOVAs). For the RT data, the main effects of relatedness $[F(1,17)$ $\left.=5.27, M S_{\mathrm{c}}=3,840.5, p<.05\right]$, SOA $[F(2,34)=$ $\left.10.18, M S_{\mathrm{e}}=5,912.4, p<.001\right]$, and intonation $[F(1,17)$ $\left.=21.9, M S_{\mathrm{e}}=16,464.8, p<.0001\right]$ were significant. Responses were faster for related trials than for unrelated trials, for longer primes than for shorter primes, and for foils than for targets.

The interaction of intonation and relatedness was significant $\left[F(1,17)=7.31, M S_{e}=7,905.8, p<.05\right]$. The nature of this interaction was faster RTs to related targets than to unrelated targets, but an opposite tendency for foils. Other two-way interactions and the three-way interaction were not significant. 

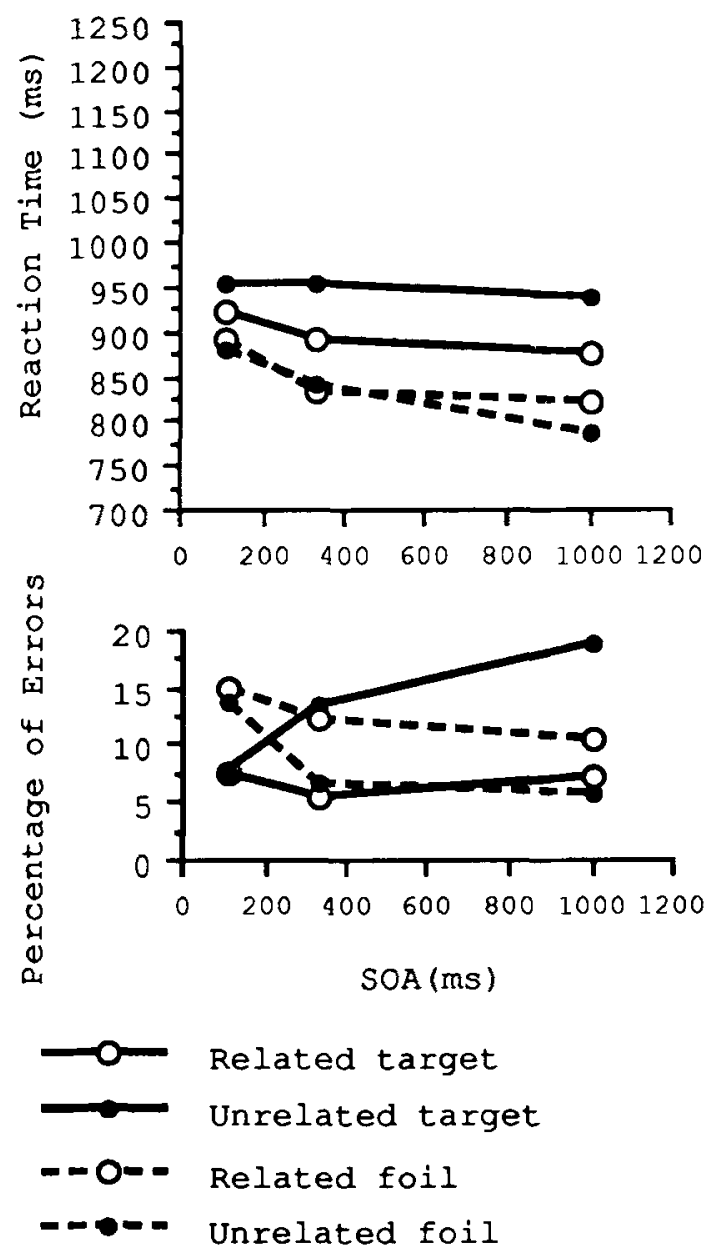

Figure 1. Average reaction times and error percentages for Experiment 1. Trials were randomized by SOA. Duration of the prime was equal to the SOA. SOAs were 111, 333, and 1,000 msec.

For the error data, there were no significant main effects. The intonation $\times$ relatedness interaction was significant $\left[F(1,17)=13.46, M S_{e}=108.26, p<.01\right]$. Fewer errors were made to related targets than to unrelated targets, but the opposite was true for foils. The SOA $\times$ intonation interaction was also significant $[F(2,34)$ $\left.=8.0, M S_{e}=77.90, p<.01\right]$. The nature of this interaction was more errors for targets with longer SOAs but not with shorter SOAs. The main cause of this effect was a large increase in errors to unrelated targets with longer primes. The three-way interaction was also significant $\left[F(2,34)=6.75, M S_{e}=45.57, p<.05\right]$. With the shortest primes, accuracy was unaffected by the relationship between prime and target. With the longer primes, there were fewer errors for related targets than for unrelated targets and more errors for related foils than for unrelated foils.

\section{Discussion}

The results of Experiment 1 replicate the results of Bharucha and Stoeckig $(1986,1987)$ and extend the finding to primes as short as $111 \mathrm{msec}$. In particular, there was an overall advantage for related chords over unrelated chords as well as the predicted interaction between relatedness and intonation. These relatedness effects demonstrate that judgments of a chord's intonation are influenced by its relationship to a previous chord, thereby providing evidence of a representation of chord relatedness.

The relatedness of the shortest primes did not have any effect on errors. For the RT data, however, the effects of the prime were observed even for the shortest primes and were not affected by the duration of the prime.

\section{EXPERIMENT 2}

In Experiment 2, a wider range of prime durations was used in an attempt to capture the development of the priming effect.

\section{Method}

The stimuli, apparatus, and procedure were the same as in Experiment 1, except for the use of four different prime durations ( 50 , $500,1,500$, and 2,500 msec). In Experiment 2, there were a total of 224 trials, which consisted of 14 replications of each of the 16 conditions. Order of trials was randomized for each subject. The practice session for Experiment 2 consisted of 16 trials, one of each possible combination of SOA, relatedness, and intonation.

The subjects were 20 Dartmouth College undergraduates with 7.75 years of experience on a musical instrument or voice on average, with a range from 0 to 13 years. Four subjects in this group reported having absolute pitch. One of those also reported loss of hearing in one ear.

\section{Results}

Average RTs and errors can be found in Figure 2. For the RT data, the main effects of all three variables were significant [relatedness, $F(1,19)=38.24, M S_{e}=$ $4,877.8$; SOA, $F(3,57)=42.03, M S_{\mathrm{e}}=48,123$; intonation, $F(1,19)=45.6, M S_{\mathrm{e}}=18,407.8$; all $\left.p s<.0001\right]$. Responses were faster in related trials than in unrelated trials. Responses were slower with the shortest primes than with the three longer primes, but did not differ among the longer three primes. Responses were faster for foils than for targets.

As in Experiment 1, the intonation $\times$ relatedness interaction was significant $\left[F(1,19)=32.63, M S_{\mathrm{e}}=20,584.8\right.$, $p<.0001$ ]. Responses were faster to related targets than to unrelated targets, but there was an opposite tendency for the foils. Unlike the results of Experiment 1, the SOA $X$ relatedness interaction and the three-way interaction were also significant $\left[F(3,57)=6.07, M S_{\mathrm{c}}=6,110.7\right.$, $p<.001$, and $F(3,57)=11.26, M S_{\mathrm{e}}=5,989.5, p<$ .0001 , for the two-way and the three-way interactions, respectively]. The SOA $\times$ relatedness interaction stemmed from the fact that reactions were faster to related chords than to unrelated chords with the three longer primes but not with the 50 -msec primes. The three-way interaction was a result of much larger differences between RTs to related and unrelated targets with the three longer prime durations than with the 50-msec prime.

The main effects of relatedness $[F(1,19)=15.16$, $\left.M S_{\mathrm{e}}=75.47, p<.001\right]$ and intonation $[F(1,19)=4.42$, $\left.M S_{\mathrm{e}}=81.32, p<.05\right]$ were also significant for the er- 

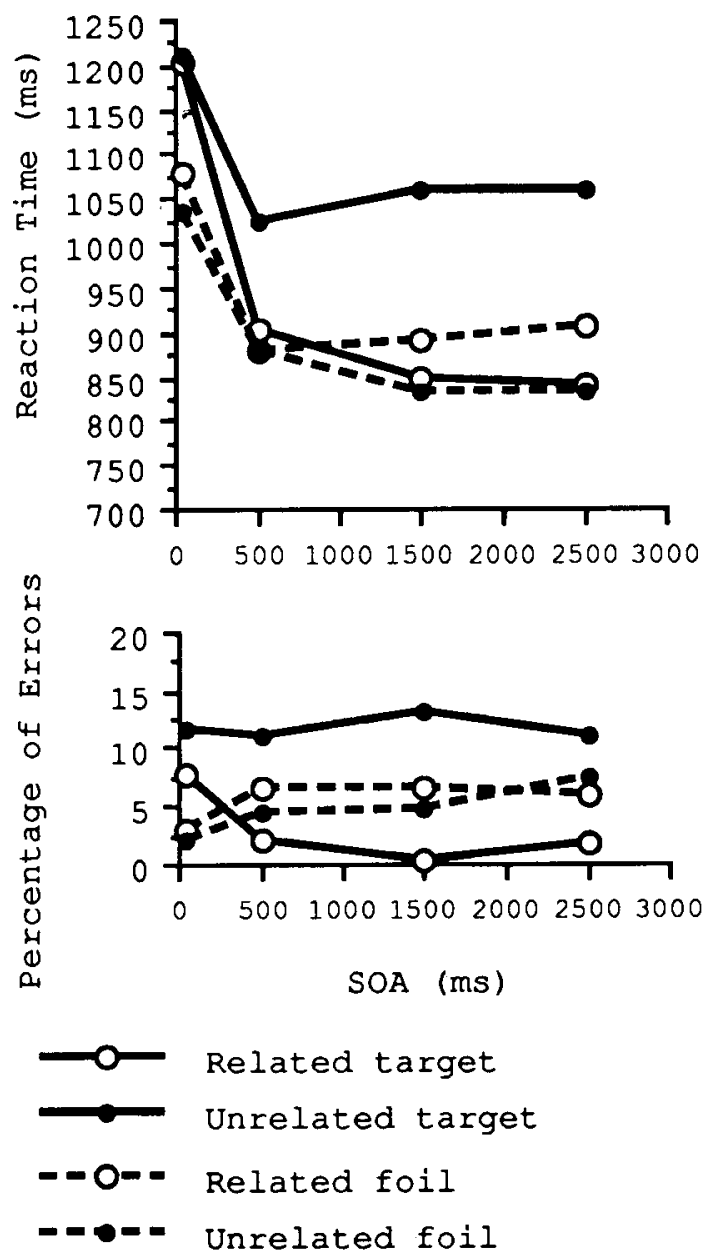

Figure 2. Average reaction times and error percentages for Experiment 2. Trials were randomized by SOA. Duration of the prime was equal to the SOA. SOAs were 50,500, 1,500, and 2,500 msec.

ror data. The subjects made fewer errors in related trials than in unrelated trials and fewer errors to foils than to targets. A significant interaction of relatedness and intonation was parallel to the interaction observed for the RT data and also the interaction observed in Experiment 1 $\left[F(1,19)=6.79, M S_{e}=255.37, p<.05\right]$. That is, errors were fewer for related targets than for unrelated targets, and there was little difference between error rates to related and unrelated foils. The three-way interaction for the error data was not significant. This signified that the relatedness $X$ intonation interaction was present even with the 50-msec primes.

\section{Discussion}

The advantage of related targets over unrelated targets in terms of faster RTs was drastically reduced with 50msec primes. There still was an advantage in the form of fewer errors. This trend was smaller than, but not significantly different from, the analogous effect with the longer primes.
Because of the extreme shortness of the 50-msec prime and random order of trials, the subjects reported having difficulty in detecting the prime in the 50-msec-prime trials. The unpredictability of the onset of the prime was eliminated in Experiment 3, with the purpose of enhancing the effects of the very short primes.

\section{EXPERIMENT 3}

Experiment 3 involved 50-msec primes only. Trials were blocked by SOA in order to increase the temporal predictability of the beginning of the prime. SOA (and ISI, which was correlated) was manipulated independently of the duration of the prime.

\section{Method}

The method was similar to that of Experiment 2. However, in Experiment 3, the subjects received the trials in four blocks; each block of trials included trials with one prime-target SOA only. Another change from Experiment 2 was cutting the prime chord after the first $50 \mathrm{msec}$ in each trial and filling the rest of the SOA with a silent period. In Experiment 3, responses were made by pressing two buttons on a response box.

The subjects were 17 Dartmouth College undergraduates. Average number of years of experience on a musical instrument or voice was 6.03 , ranging from 0 to 16 years. One of the subjects reported having absolute pitch.

\section{Results}

Average RTs and errors can be found in Figure 3. For the RTs, the effect of relatedness was not significant. Significant main effects of SOA $\left[F(3,48)=5.04, M S_{\mathrm{c}}=\right.$ $18,189.9, p<.01]$ and target intonation $[F(1,16)=6.02$, $\left.M S_{\mathrm{e}}=17,336.2, p<.05\right]$ were replicated in Experiment 3. RTs were longer with the 50-msec SOA than with the three longer SOAs. The subjects were again faster to respond to foils than to targets.

The intonation $\times$ relatedness interaction was significant $\left[F(1,16)=10.81, M S_{\mathrm{e}}=4,644.3, p<.05\right]$. Responses were faster to related than to unrelated targets, and to unrelated foils than to related foils. Unlike the previous experiments, the magnitudes of these differences were similar, resulting in the absence of any advantage, on average, for related chords over unrelated chords. The three-way interaction was not significant.

The only reliable effect for the error data was that of SOA $\left[F(3,46)=3.07, M S_{c}=26.98, p<.05\right]$. More errors were made with the 50- and 2,500-msec SOAs than with the two intermediate SOAs.

\section{Discussion}

In Experiment 3, it was demonstrated that it is possible to obtain reliable priming effects with 50 -msec primes presented at SOAs that ranged from 50 to $2,500 \mathrm{msec}$. With the 50-msec SOA, responses were slower overall than were responses with longer SOAs, but the magnitude of the intonation $\times$ relatedness interaction was comparable for all SOAs.

Longer RTs with the 50-msec SOA may be a result of the onset of the prime chord serving as a precue for the 

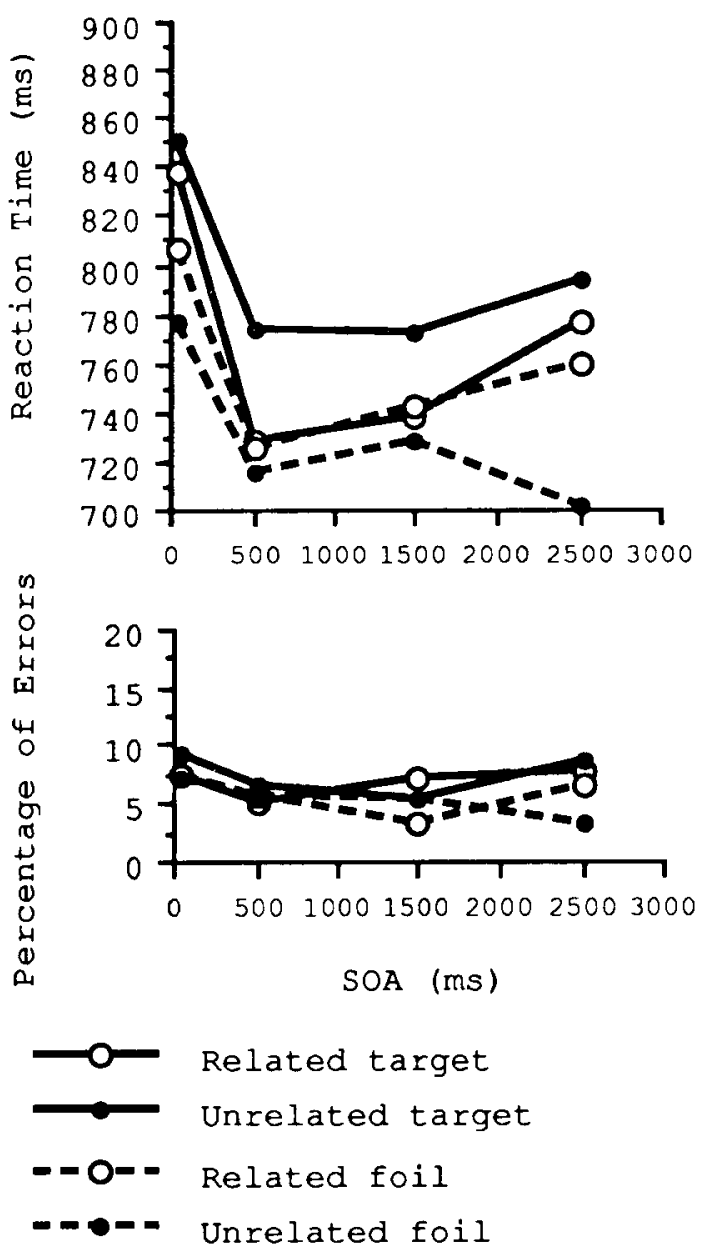

Figure 3. Average reaction times and error percentages for Experiment 3. Trials were blocked by SOA. Duration of the prime was always 50 msec. SOAs were $50,500,1,500$, and 2,500 msec.

onset of the chord to be judged. A similar effect was observed by Posner, Klein, Summers, and Buggie (1973) in a visual discrimination experiment. The response to a visual stimulus was faster when a warning signal, which was a 50-msec tone, preceded it with a 450-msec SOA, relative to that with a $50-\mathrm{msec}$ SOA. This finding, together with the absence of a three-way interaction in the present experiment, suggests that slower responses with the 50msec SOA may be a precuing effect that is not specifically related to the priming effect.

Another observed effect was that a 50-msec prime could be effective in creating a priming effect after a silent period of as long as $2,450 \mathrm{msec}$. It has been demonstrated that recognition memory for tones shows only a slight decline after a silent retention interval (Kallman \& Massaro, 1979, 1983; Massaro, 1970b), and presentation of another auditory stimulus leads to reduction in recognition performance. The results of Experiment 3 showed that this kind of memory for a sound stimulus can be effective in sustaining chord priming as well as a recognition judgment after a short silent interval. Experiment 4 was designed to address the involvement of auditory sensory memory in the priming effect with a delay after the prime chord.

\section{EXPERIMENT 4}

One contribution to the priming effects observed when a silent period separated the prime chord and the chord that was to be judged could come from auditory sensory memory. Specifically, the prime could have been held in auditory sensory memory and perceptual processing of the prime could have continued after the end of the physical stimulus (Kallman \& Massaro, 1979, 1983; Massaro, 1970a). This would increase the effective duration of the prime.

Experiment 4 addressed the question of the contribution of auditory sensory memory to the priming effect with long ISIs. One way of eliminating the contents of auditory sensory memory is to present another auditory stimulus at the end of the prime chord (Kallman \& Massaro, 1979; Massaro, 1970b). A noise mask presented exactly at the end of the prime was used for this purpose in Experiment 4.

Kallman and Massaro (1979; see also Massaro, 1970b) found that a tone mask was more effective than a noise mask in short-term tone-recognition experiments. Since the introduction of new tones in a trial would change harmonic expectancies as well, a noise mask was used in this experiment as a harmonically neutral stimulus.

\section{Method}

Subjects. The subjects were 24 undergraduates at Dartmouth College who participated for extra credit in an introductory psychology course. The average number of years of practice on a musical instrument or voice was 5.38, with a range from 0 to 11 years.

Apparatus. The apparatus was the same as that used in the previous experiments, except that the noise mask was created by a MacAdios II system (GW Instruments) controlled by the Macintosh II. The chords and the noise mask were combined by a Kawai MX8SR mixer and presented to the subjects through headphones.

Stimuli. Experiment 4 incorporated the three longer prime-target SOAs used in Experiment $3(500,1,500$, and 2,500 $\mathrm{msec})$ with the same stimuli. The 50-msec SOA was not included in this experiment, because it had not been followed by a silent period in Experiment 3 . There were 18 repetitions of each of the 12 conditions. Trials were blocked by SOA.

The major difference from Experiment 3 was that a noise mask was heard following the prime chord in each trial. This mask contained all frequencies up to $10 \mathrm{kHz}$, with uniform amplitude levels. This range of frequencies covered the range of frequencies that were present in the stimulus chords. The duration of the noise mask was $250 \mathrm{msec}$ in all trials.

\section{Results}

Average RTs and error percentages are presented in Figure 4. For the RTs, the main effect of SOA approached significance $\left[F(2,46)=2.65, M S_{\mathrm{e}}=391,164, p<.09\right]$. RTs tended to increase for longer SOAs. This pattern was similar to the one in Experiment 3 for the longer three SOAs. Main effects of the other two factors were not close to significance. 

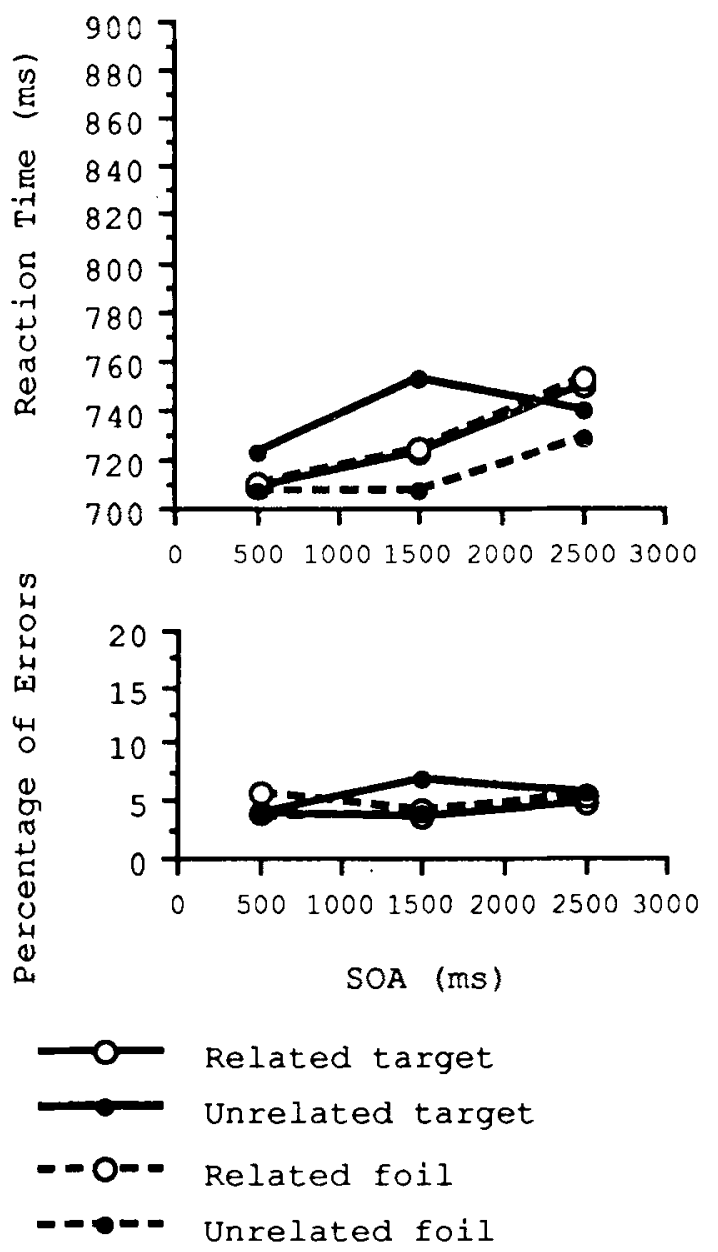

Figure 4. Average reaction times and error percentages for Experiment 4. Trials were blocked by SOA. Duration of the prime was always 50 msec. A noise mask of 250 -msec duration was presented at the end of the prime. SOAs were $500,1,500$, and $2,500 \mathrm{msec}$.

The intonation $\times$ relatedness interaction was replicated in Experiment $4\left[F(1,23)=4.77, M S_{e}=61,453, p<\right.$ $.05]$. The SOA $\times$ relatedness interaction approached significance $\left[F(2,46)=2.7, M S_{\mathrm{e}}=74,696, p<.08\right]$. For the shorter two SOAs, responses were faster, on average, in related trials than in unrelated trials, whereas for the longest SOA, responses were faster in unrelated trials. This trend was found to be significant in an analysis of the RT data from the 500-, 1,500-, and 2,500-msec ISI conditions of Experiments 3 and 4 combined $[F(2,78)=$ $\left.4.50, M S_{\mathrm{e}}=2,320.5, p<.05\right]$. The only other significant effects in this analysis were faster RTs to foils than to targets $\left[F(1,39)=4.42, M S_{\mathrm{e}}=12,330.6, p<.05\right]$ and the intonation $\times$ relatedness interaction observed in both experiments $\left[F(1,39)=17.06, M S_{\mathrm{e}}=2,882.8, p<\right.$ $.001]$. None of the effects involving the masking factor reached significance in this analysis.

Only the intonation $\times$ relatedness interaction approached significance for the error data of Experiment $4[F(1,23)=$
3.18, $\left.M S_{c}=513.5, p<.09\right]$. This effect was in the direction of fewer errors for related targets than for unrelated targets, and fewer errors for unrelated foils than for related foils.

\section{Discussion}

By the replication of the intonation $x$ relatedness interaction and the absence of a significant three-way interaction, we can conclude that priming was present and did not change in magnitude over the ISIs tested. A change in the effects of the prime with varying ISIs that was observed in Experiments 3 and 4 was shorter RTs, on average, to related chords than to unrelated chords with the shorter ISIs, but a difference in the opposite direction for the 2,450-msec ISI.

\section{GENERAL DISCUSSION}

We can conclude that the processes underlying chord priming are engaged rapidly (as early as $\mathbf{5 0} \mathrm{msec}$ ) and persist for at least as long as $2,450 \mathrm{msec}$ in spite of masking noise. The effect with a 2,450-msec delay was different from the effects observed with shorter delays. With shorter delays, responses were faster, on average, to chords preceded by related chords than to those preceded by unrelated chords, whereas this difference was reversed with the 2,450-msec ISI. Nevertheless, the nature of the relatedness $x$ intonation interaction was the same as that for shorter delays.

Kallman and Massaro $(1979,1983)$ argued that presentation of a masking stimulus interrupts the perceptual processing of a previously presented sound. By this reasoning, in Experiment 4, chord-priming effects were observed without the benefit of any further perceptual processing after the first $50 \mathrm{msec}$. This suggests that, by this time, the processing of harmonic relationships continues independent of any involvement of an auditory sensory store, which would support the idea of a cognitive, rather than a sensory, basis for the priming effect.

One general caveat about our results is the correlation between the harmonic proximity of chord pairs and the overlap of their frequency spectra. We do not believe, however, that the overlapping frequency spectra of the related chords was responsible for the priming effects in light of the Bharucha and Stoeckig (1987) results, which showed chord priming in the absence of overlapping spectra. Chord priming with short SOAs in the absence of overlapping frequency spectra will be the subject of further research.

\section{REFERENCES}

Bharucha, J. J. (1987a). MUSACT: A connectionist model of musical harmony. In Proceedings of the Ninth Annual Conference of the Cognitive Science Society (pp. 508-517). Hillsdale, NJ: Erlbaum.

BHARUCHA, J. J. (1987b). Music cognition and perceptual facilitation: A connectionist framework. Music Perception, 5, 1-30.

Bharucha, J. J. (1991). Pitch, harmony, and neural nets: A psychological perspective. In P. Todd \& G. Loy (Eds.), Music and connectionism (pp. 84-99). Cambridge: MIT Press. 
Bharucha, J. J., Krumhansl, C. L. (1983). The representation of harmonic structure in music: Hierarchies of stability as a function of context. Cognition, 13, 63-102.

Bharucha, J. J., Stoeckig, K. (1986). Reaction time and musical expectancy: Priming of chords. Journal of Experimental Psychology: Human Perception \& Pefformance, 12, 1-8.

Bharucha, J. J., Stoeckig, K. (1987). Priming of chords: Spreading activation or overlapping frequency spectra? Perception \& Psychophysics, 41, 519-524.

Fletcher, H., MUNson, W. A. (1933). Loudness, its definition, measurement and calculation. Journal of the Acoustical Society of America, 5, 82-108.

Kallman, H. J., Massaro, D. W. (1979). Similarity effects in backward recognition masking. Journal of Experimental Psychology: Human Perception \& Performance, 5, 110-128.

Kallman, H. J., Massaro, D. W. (1983). Backward masking, the suffix effect, and perceptual storage. Joumal of Experimental Psychology: Learning, Memory, \& Cognition, 9, 312-327.

Krumhansl, C. L., Bharucha, J. J., \& Castellano, M. A. (1982). Key distance effects on perceived harmonic structure in music. Perception \& Psychophysics, 32, 96-108.
Krumhansl, C. L., Bharucha, J. J., \& Kessler, E. J. (1982). Perceived harmonic structure of chords in three related musical keys. Joumal of Experimental Psychology: Human Perception \& Performance, 8, 24-36.

Massaro, D. W. (1970a). Perceptual auditory images. Journal of Experimental Psychology, 85, 411-417.

MASSARO, D. W. (1970b). Retroactive interference in the short-term recognition memory for pitch. Journal of Experimental Psychology, 83, 32-39.

Meyer, L. (1956). Emotion and meaning in music. Chicago: University of Chicago Press

Posner, M. I., Klein, R., Summers, J., Buggie, S. (1973). On the selection of signals. Memory \& Cognition, 1, 2-12.

ShEPARD, R. N. (1964). Circularity in judgments of relative pitch. Journal of the Acoustical Society of America, 36, 2346-2353.

(Manuscript received March 18, 1991: revision accepted for publication August 24, 1991.) 